\title{
Towards a more responsive health system?
}

R esponsiveness" has become a key aim of NHS policy, but what does it mean? The following articles show that there are a number of ways to approach the issue at different levels. Some seek to involve patients in the planning of care, others to reach out to groups who find it difficult to access health care. For many, responsiveness has economic connotations. Other articles consider ways to make clinical teams and organisational management more responsive.

Please visit the QSHC website

(http://www.qshc.com) for links to these articles - many to full text. render them less willing and able to obtain emergency contraception." The authors suggest that ways should be found of providing emergency contraception that take these factors into account.

$\Delta$ Free C, Lee R, Ogden J. Young women's accounts of factors influencing their use and non-use of emergency contraception: in-depth interview study. BM 2002;325:1393

\section{Changing services based on understanding access from user} perspectives A paper in the BM explores "women's accounts of their use and non-use of emergency contraception". Although recent efforts have increased access "among teenagers in inner city areas, there has been low use of free emergency contraception provided by local pharmacies". The researchers highlight some barriers in the circumstances and minds of young women to taking up improved access, based on 30 in-depth interviews.

Women with the "strongest desire to avoid pregnancy" - and likely to use emergency contraception, if necessary - "tended to have strong aspirations for education, careers, travel, or lifestyle". Pregnancy for this group would be a "complete disaster".

The paper describes different kinds of "contraceptive behaviour" among women, ranging from "obsessive concern" to a sense of having a "low vulnerability" to pregnancy. "Evaluations of the risk of pregnancy conferred by different contraceptive behaviours were based on advice and experience. In particular, the women cited their own or friends' experience in becoming or not becoming pregnant", suggesting that women in different social circumstances build up quite different contraceptive behaviours.

Being in the position of needing emergency contraception was seen as "a personal failure" and shameful, particularly if it was the second or third time. Women are concerned about what people will think of their sexual behaviour, and this can prevent them from accessing emergency contraception. "A few women disassociated themselves from emergency contraception entirely, reporting that they were not the kind of person who would ever need it". There is a lack of knowledge about the treatment and fear of harmful effects. "One woman who had used emergency contraception was concerned that it was similar to having an abortion".

Sometimes women are concerned about meeting healthcare professionals and the judgement it may involve. Women prefer friendly and matter of fact exchanges. "Consultations that focused largely on the risks that had been taken made the women feel told off and reluctant to re-attend. A few women reported being angry about the way healthcare professionals had treated them."

The authors "identified links between a strong motivation to avoid pregnancy and the perception that the risk of pregnancy is high". They also draw attention to circumstance and situation and acknowledging differences in behaviour. "In public discourse the risks associated with particular courses of action are often discussed in a way that renders their situational and contingent character invisible". "Those women who thought it easier to avoid emergency contraception rather than face their own anxiety, sense of guilt, and concern about what others might think were teenagers who either lived in disadvantaged areas or were homeless. The concerns and personal resources of such women may

\section{Do initiatives to involve patients in the planning of health care make for a more responsive health}

system? "Over the past 20 years, governments throughout western Europe and North America have encouraged patients to contribute to the planning and development of health services". "Underlying these changes is the belief that involving patients leads to more accessible and acceptable services and improves the health and quality of life of patients". This paper from the BM undertakes a "systematic review of involving patients in the planning and development of health care". Forty two papers were analysed qualitatively of which $31(74 \%)$ were case studies.

Although "involving patients is becoming less discretionary and more compulsory for the providers of services, engaging patients is not an easy task, and no consensus on which methods are most effective under different circumstances exists". This paper aims to establish what is known about patient involvement. Because most papers relied on field worker reports (there were no experimental or comparative research designs), "data analysis was restricted to a narrative account of outcomes of involving patients and the nature of the evidence used to support these claims. Because no system for rating the quality of information in case reports exist, we could not assign quality ratings to the papers we included."

Several papers commented that patients who participated "welcomed the opportunity to be involved and that their self-esteem improved as a result of their contributions". Some studies describe tensions between patients and staff in negotiating changes although others comment that "staff involved in initiatives found the experience rewarding". One of the most common effects of involvement was "the production of new or improved sources of information for patients". Other examples of changes were in improving/simplifying appointment procedures for services.

Eight of the reports suggest that "initiatives had a more general effect on organisational attitudes to involving patients". "The culture of the organisations changed in a way that made them more open to involving patients". But there is little evidence offered to substantiate this claim and the authors note the concerns expressed by some researchers that "involving patients was used to legitimise decisions that would have been made whether or not patients supported them"

The overall impact of involving patients has been done through surveys of patients or those involved in an initiative. There is evidence that involving patients in decisions does generate ideas for change and, in some cases, these have been implemented. But, as the authors note, "the effects of involvement on accessibility and acceptability of services or impact on the satisfaction, health, or quality of life of patients has not been examined". There are a number of factors that might explain this. Initiatives may have had 
broader aims: the process of involvement may have been seen as the end point. Although involving patients is presented as a democratic trend, it can be argued that it is a veil to legitimise otherwise unpopular decisions by managers and policymakers.

The central problem is the lack of methodologies to identity the impact of patient involvement; these are likely to be complex, affecting different aspects of service in different ways. "Patient involvement is not without its costs, and including outcome measures in future evaluations of involving patients could enable comparisons of different approaches and evaluation of the effects of suggestions made by patients".

\ Crawford M, Rutter D, Manley C, et al. Systematic review of involving patients in the planning and development of health care. BM 2002;325: 1263

\section{Does publishing clinical information to inform users make} services more responsive? A qualitative study in the BM examined the "attitudes of service users, general practitioners, and clinical governance leads based in primary care trusts to the public dissemination of comparative reports on quality of care in general practice". The paper set out to inform policy and practice of information disclosure in primary care.

The international trend to publish quality reports in "so called report cards" is "a central component of UK government plans for the reform of the NHS". The report cards are "expected to improve the accountability of service providers, stimulate improvements in quality and encourage service users and purchasers to access high quality providers". "Alongside these potential benefits are well recognised risks: a tendency for organisations to concentrate their efforts on the reported outcomes, a preoccupation with brief reporting cycles at the expense of long term strategic planning, and the potential for misrepresenting or even falsifying data" Quality reports are more usual in America, but "consumers tend not to value or make use of comparative data".

The initial reaction from the 12 focus groups (four of service users, four of GPs, and four of clinical managers based in primary care trusts) was strongly negative. "The dominant feeling expressed particularly strongly by the service users was that such reports were unnecessary, unfair and unwanted". The service users did not want to accept that there was an important variation in the quality of care provided by different practices; they thought differences were the result of factors outside the control of the practices themselves.

Over time, these negative reactions changed and became more positive. The initial negative reaction related to the practicalities "the way government will use it"-and there was particular concern about the political motivation of disclosure. Doctors fear the profession will be undermined and users are keen to protect their local practices from political interference. People are unwilling to treat health as a commodity. "You don't change doctors like you change cars", said one service user. "The unwillingness to exercise choice related to the level of confidence they had in the comparative information. Even if the data suggested that their own practice or doctor was substandard, they placed greater trust in their own experience or that of friends and family."

"All three stakeholder groups expressed concern that general practitioners would distort their behaviour to improve their reported performance. The clinical governance leads supported the use of comparative information for internal purposes." They expressed concern that public release of information would encourage a "name and shame" culture in general practice.

The authors say that "it is perhaps inappropriate to expect members of the public in the UK, so long deprived of information about the performance of the health service, to suddenly behave like rational consumers, weighing up the costs and benefits, making judgments about relative performance, and refusing to access apparently poor practices". Because political initiatives are regarded with such caution, it is suggested that "non-governmental initiatives . . .might be seen in a more positive light".

A Marshall M, Hiscock J, Sibbald B. Attitudes to the public release of comparative information on the quality of general practice care: qualitative study. BM 2002;325: 1278

\section{Does increasing market influence make health services more}

responsive? In OECD Health's assessment of health systems, responsiveness is a key measure. Its inclusion has been criticised for overvaluing market based systems with economic conceptions of choice. But a paper published in Pharmacoeconomics defends and promotes market reform, arguing that greater exposure to the market coupled with the values of socialised systems is the shortest route to a responsive service.

Reform is needed because the traditional healthcare organisation "was not designed to accommodate a real consumer influence". In the welfare state "the patients' specific demands had to be neglected so that equality was not put at risk-need not demand was the key to the distribution of services". "Officially it still is, but in practice this policy becomes more and more difficult to maintain". Why?

It is because "new healthcare consumers" are fundamentally different from those in the past. "Not only are they better educated, more integrated into social networks, and better financially than previous generations, but in general they are also more accustomed to making long range decisions by themselves". In tandem, healthcare professionals are demanding increasing "selfgovernance in order to find better solutions for local problems and incentives that reward initiative and competence-qualities that are still often in opposition to traditional healthcare". Major reform is needed to meet the needs of consumers and professionals: "You cannot meet the expectations of future workers without dramatically revamping the organisational structure by breaking up big units into small ones, thus providing workers with more control and greater incentives to be problem solvers".

The author sees the development of a European healthcare market as inevitable. "When there are 'EU price tags' for hip replacement, heart surgery, or cancer therapies, the influence of the consumer will grow even more". (The author does not explain why or how.)

The "Stockholm revolution" is described-reform in Sweden's capital that has served as an inspiration to both Alan Milburn and Liam Fox. Diagnostic related groups (DRGs) have been introduced, hospitals are to be converted to publicly owned companies ("creating opportunities for a more entrepreneurial approach"), purchasers and providers have been separated, a maximum of 3 months waiting will be enforced, and personnel are being encouraged to start companies to take over the operation of primary clinics "and other contracted facilities". There has also been a "rapid expansion of the capacity to provide consumer information, in order to support active consumer behaviour".

Among the successes of the "revolution" have been increases in capacity and productivity (up by $19 \%$ ), and a $22 \%$ reduction in waiting times within the first year. It is obvious why the Stockholm model has attracted political interest. Nevertheless, it is difficult to see from Hjertqvist's comments how the consumer's (or patient's) voice has become more influential. In what sense is the system more responsive? It seems responsiveness is equated with economic and managerial notions. An increase in responsiveness relies upon increasing economically rational consumer behaviour, which is difficult to imagine. Articles in previous JournalScans and the paper above by Marshall et al show that assumptions of economic rationality in the use of health care fail to engage with counter-rationale. There will no doubt continue to be much debate about the extent to which market based reform improves health care.

$\Delta$ Hiertqvist J. Meeting the challenges to European healthcare: lessons learned from the "Stockholm revolution". Pharmacoeconomics 2002;20(Suppl 3):47-53

\section{Becoming responsive to alternative and complementary health \\ therapies? A study in the American Journal of Public} Health examines the health demographics of people using complementary and alternative health therapies in four English counties (Berkshire, Buckinghamshire, Northamptonshire and 
Oxfordshire). Almost 9000 people completed a postal survey, detailing any chronic illness and consultations-alternative, complementary or traditional - they had had during the previous year.

More than half $(60 \%)$ of those who visited an alternative practitioner had a chronic illness. Those who consulted complementary and alternative practitioners tended to visit their GPs more frequently than those who did not. "The most likely predictors of use of complementary and alternative health practitioners were long standing illness, non-manual social class, female sex, and high levels of GP service use". Users of alternative therapy who did not report chronic illness were also more likely than non-users of alternative therapies to consult their GP frequently through the year. Certain conditions predicted the use of particular therapies; "asthma and anxiety predicted visits to herbalists". The most common reason for seeking alternative therapy was for pain relief.

The authors ask whether the NHS should incorporate alternative therapies within its provision, given that people are prepared to pay out of pocket for these services. They think not. If the NHS were to incorporate such treatments, the authors estimate it would add a minimum of $£ 450 \mathrm{~m}$ to the NHS budget. There is no financial estimate placed on the improved health that might result, nor any discussion of likely trends in demand for alternative and complementary treatments.

A Ong C, Peterson S, Bodeker G, et al. Health status of people using complementary and alternative medical practitioner services in 4 English counties. Am J Public Health 2002;92:1653-6

\section{Making clinical teams more}

responsive A paper from the Health Care Management Review evaluates an initiative to teach continuous quality improvement (CQI) methods to 25 teams of "nurses, physicians, medical trainees, and other health professionals" so that they improve problem solving skills and reduce fragmentation within teams.

"Teams are encouraged to begin by selecting a patient population based on high volume or some other need, as the focus for their improvement project". The project aimed to "lead to changes in team-problem solving effectiveness and patient outcomes". Teams were instructed in CQI methods and their behaviour in problem solving observed. The research team tested people in their retention of taught materials to gauge whether knowledge of $\mathrm{CQ}$ increased in the team. A team's ability to problem solve was judged according to its adherence to the models taught in collective practice. Finally, each team was asked to "collect data on the outcome indicators they had identified for their patient population as the basis for judging the success of their 'change idea'"

The unstated aim of the initiative was to make clinical teams more responsive to modernisation and to incorporate associated activities as part of their work. Nine of the 25 teams were adjudged to have had some success in achieving improvement. Why were some successful and others less so? "Successful and unsuccessful teams did not differ in their baseline level of CQI knowledge and dysfunctional groups interactions". However, "teams that demonstrated an improvement in an outcome or process indicator had significantly higher scores for problem-solving effectiveness". Although training led to improvements in CQl knowledge, this was nowhere retained after 9 months and, at this point, "most teams were no longer engaged in their improvement work in spite of the fact that we had hoped teams would continue to apply their knowledge as part of everyday practice". "What we actually found was that successful teams reported higher functional group interactions than unsuccessful teams, even at baseline".

The paper concludes with a couple of interesting ideas: firstly, that CQI training should be "just in time" and initiatives should focus on genuine concerns and collective aims and, secondly, that initiatives need to be owned more locally with team members themselves addressing the functionality of relations.

$\Delta$ Irvine D, Ross Baker D, Murray M, et al. Achieving clinical improvement: an interdisciplinary intervention. Health Care Manage Rev 2002;27:42-56

\section{Making management theory and practice more responsive to each}

other An article written in Health Care Management Review considers the relationship between theory and practice in health management. The author has held academic and management positions and wants to see a greater bond and exchange between these activities. The problem is that it is difficult for managers to pursue academic interests, and virtually unheard of for academics to spend a portion of time managing. The demands of these roles are too great to be combined.

"In my own practitioner career, which includes a series of senior line management positions within increasingly large physician group practices, pursuing academic interests has been difficult. I was attracted to several management positions with academic faculty practices precisely by the proximity to the academic enterprise, and a number of faculty physicians over the years have been interested in collaboration with a 'management type'. I have found however, that the 60-80 hour week requirements (at least as I allow myself to perceive them) for effective executive performance. . made research and writing time nearly impossible to schedule. Perhaps this was due to my preference for line management roles."

The article suggests that health service managers need to be more scholarly-"a discoverer, consumer, and disseminator of knowledge". It would aid research if "knowledge could be co-produced" by researchers and managers "synthesising the different and partial understandings that academics and practitioners learn by themselves".

"Many management faculties today have little or no management experience". Academics need to engage more with practitioner issues. "My practitioner career focus . . . very much influences my long-term research interests. In the manner that political advisers frequently chant 'It's the economy, stupid', my personal health management mantra is 'It's the doctors, stupid'. What gets done in healthcare delivery, which new models gain adherents, which CEOs achieve lengthy tenures, what technology diffuses rapidly, and a host of their process and outcome variables depend to a great extent on how physicians are educated in our medical schools, aligned with our systems, involved in leadership roles, compensated, and organizationally structured."

"Of course, medical sociology, sociology in general, social psychology, political science, health economics, organizational behavior and other theoretical and disciplinary underpinnings help us to understand how physicians choose to behave and participate in various delivery systems, [but] much of how this all takes place . . is quite local, deterministic and pragmatic."

One of the problems is that managers do not read journal articles. "I am sure there are some . . . but I have not met them." I suspect there are at least two reasons. "Once out in the field, striving in their careers, constantly interrupted, nurturing families, and active in their communities, practitioners simply do not have the time to read lengthy, often dense academic studies". "The second reason is what some colleague managers and I call the 'R-square phenomenon', the best model the researcher can test explains 0.22 of variance". "The bright manager does not come away with much of a take-home for her reading efforts".

"A very interesting model to help bridge the practitioneracademic gap might be a health management equivalent of the Harvard Business Review, with readable articles summing up streams and threads of important research primarily for consumption by health management practitioners".

$\Delta$ Lunn R. Balancing careers in health management practice and the academy: issues, synergies, rewards and piffalls. Health Care Manage Rev 2002;27:69-75

T Smith

Research Associate, Judge Institute of Management, Cambridge University, Cambridge CB2 1AG UK; ts271@cam.ac.uk 